\title{
EVENTOS ADVERSOS E FATORES RELACIONADOS NO DIA DO TRANSPLANTE DE CÉLULAS-TRONCO HEMATOPOÉTICAS
}

Andressa Gomes Melo ${ }^{1} \quad$ http://orcid.org/0000-0003-2645-1937

Juliana Bastoni da Silva ${ }^{2}$ http://orcid.org/0000-0002-6642-8910

Objetivo: Investigar os eventos adversos, classificá-los conforme a gravidade e identificar seus fatores relacionados no dia da infusão de células-tronco hematopoéticas. Método: Estudo transversal prospectivo, com 85 pacientes do transplante de células-tronco hematopoéticas (TCTH) de um hospital do Estado de São Paulo, Brasil. Os eventos adversos (EA) foram identificados e classificados pelo Common Terminology Criteria for Adverse Euents. Para análise

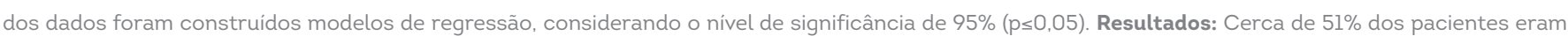
do sexo feminino, 41,2\% apresentaram índice de comorbidade de risco intermediário/alto, 52,9\% eram do grupo alogênico aparentado. Pelo modelo de regressão multinomial, foram considerados fatores associados à gravidade dos EA: maior viabilidade celular ( $p=0,0352$ ) e o índice de comorbidade pré-TCTH de risco intermediário/alto ( $p=0,0040)$. No modelo de regressão linear generalizado, foram considerados fatores associados ao número de EA: maior viabilidade celular ( $p<0,0001$ ), maior volume total de bolsas infundidas ( $p=0,0011$ ), TCTH alogênico ( $p=0,0093$ ), diagnóstico de Linfoma ( $p=0,0001)$ e Mieloma Múltiplo ( $p=0,0136)$, indice de comorbidade pré-TCTH de intermediário/alto risco ( $p=0,0010)$ e criopreservação ( $p=0,0023)$. Conclusão: Pacientes de TCTH são suscetíveis a diversos fatores que os predispõe a eventos adversos, o que representa um desafio para o enfermeiro e equipe multidisciplinar. Descritores: Transplante de células-tronco hematopoéticas; Enfermagem; Enfermagem oncológica; Toxicidade; Eventos adversos.

\section{ADVERSE EVENTS AND RELATED FACTORS AT THE DAY OF HEMATOPOETIC STEM CELL TRANSPLANTATION}

Objective: Investigate adverse events, classify them according to severity and identify their related factors on the day of hematopoietic stem cell infusion. Method: Prospective cross-sectional study with 85 patients of the hematopoietic stem cell transplantation (HSCT) in a hospital in the state of São Paulo, Brazil. Adverse events (AE) have been identified and classified by the Common Terminology Criteria for Adverse Euents. For data analysis, regression models were built; significance level of $95 \%$ ( $\mathrm{p} \leq 0,05)$. Results: About 51\% of the patients were female, $41.2 \%$ had an intermediate/high risk comorbidity index, $52.9 \%$ were allogeneic group. The multinomial regression model considered factors associated with severity of AE: greater cell viability ( $p=0.0352)$ and the intermediate/high risk pre-HSCT comorbidity index ( $p=0.0040)$. In the generalized linear regression model, factors associated with the number of AE were considered: greater cell viability ( $p<0.0001)$, greater infused volume ( $p=0.0011)$, allogeneic HSCT ( $p=0.0093)$, diagnosis Lymphoma ( $p=0.0001)$ and Multiple Myeloma ( $p=0.0136)$, intermediate/ high risk pre-HSCT comorbidity index $(p=0.0010)$ and cryopreservation ( $p=0.0023)$. Conclusion: These patients are susceptible to several factors that predispose them to $A E$, which represents a challenge for nurses and multidisciplinary team.

Descriptors: Hematopoietic stem cell transplantation; Nursing; Oncology Nursing; Toxicity; Adverse events.

\section{EVENTOS ADVERSOS Y FACTORES RELACIONADOS EN EL DİA DEL TRASPLANTE DE CÉLULAS MADRE HEMATOPOÉTICAS}

Objetivo: Investigar eventos adversos, clasificarlos según su gravedad e identificar sus factores relacionados el dia de la infusión de células madre hematopoyéticas. Método: Estudio prospectivo y transversal con 85 pacientes em el trasplante de células madre hematopoyéticas (TCMH), en un hospital en el estado de São Paulo, Brasil. Los eventos adversos (EA) han sido clasificados por los criterios de terminología común para eventos adversos. Se construyeron modelos de regresión; el nivel de significancia del $95 \%$ ( $p \leq 0,05)$. Resultados: $51 \%$ eran mujeres y $52,9 \%$ pertenecía al grupo alogénico relacionado. El modelo de regresión multinomial consideró factores asociados con la gravedad de la EA: una mayor viabilidad celular ( $p=0.0352$ ) y el índice de comorbilidad pre-HSCT de riesgo intermedio/alto $(p=0.0040)$. En el modelo de regresión lineal generalizado, se consideraron factores asociados con número de EA: mayor viabilidad celular $(p<0,0001)$, mayor volumen infundido $(p=0,0011)$, TCMH alogénico $(p=0,0093)$, diagnóstico linfoma $(p=0.0001)$ y mieloma múltiple $(p=$ 0.0136), índice de comorbilidad pre-HSCT de riesgo intermedio/alto ( $p=0.0010$ ) y criopreservación ( $p=0.0023)$. Conclusión: Estos pacientes son susceptibles a varios factores que los predisponen a EA, un desafío para las enfermeras y el equipo multidisciplinario.

Descritores: Trasplante de células madre hematopoyéticas; Enfermería; Enfermería Oncológica; Toxicidad; Eventos adversos.

${ }^{1}$ Universidade Estadual de Campinas (Unicamp), SP, Brasil.

${ }^{2}$ Universidade Federal do Tocantins, TO, Brasil.

Autor correspondente: Juliana Bastoni da Silva - Email: juliana.bastoni@uft.edu.br Recebido: 08/04/20 - Aceito: 06/11/20 


\section{INTRODUÇÃO}

O transplante de células-tronco hematopoéticas (TCTH) é um tratamento com potencial de cura, para pacientes com doenças hematológicas malignas e benignas, tumores sólidos e doenças autoimunes ${ }^{(1)}$, pois pode proporcionar a reconstituição hematológica e imunológica, após exposição a altas doses de quimioterapia, associada ou não à radioterapia(2).

Cerca de 50.000 pacientes recebem TCTH no mundo anualmente, dos quais 50\% são realizados na Europa e $28 \%$ nas Américas ${ }^{(3)}$. Em 2019, o Registro Brasileiro de Transplantes computou 3805 TCTH no país, sendo 62,5\% autólogos e $37,5 \%$ alogênicos ${ }^{(4)}$.

Os transplantes podem ser qualificados em alogênico aparentado ou não, idêntico ou não, autólogo (uso de células do próprio paciente) e singênico (gêmeos idênticos) (5-6). O haploidêntico foi integrado como modalidade alternativa de transplante, devido à necessidade de ampliar a possibilidade de doadores compatíveis ${ }^{(7)}$. No haploidêntico, considera-se que algum membro da família de primeiro grau tenha características de histocompatibilidade com o receptor, em torno de $50 \%{ }^{(8)}$.

Os pacientes de TCTH podem apresentar eventos adversos (EA) durante todo o período de internação, sobretudo no dia da infusão de células-tronco hematopoéticas $(\mathrm{CTH})$. Esses EA estão relacionados a causas prováveis, descritas na literatura(5,9-10), no entanto, ainda não totalmente elucidadas. Considera-se EA qualquer sintoma, sinal ou doença desfavorável, inclusive alterações laboratoriais, temporalmente associados, mas, não necessariamente relacionados ao uso de um tratamento ou procedimento(11)

Os EA são descritos como mais comuns nos receptores de CTH criopreservadas, mas, outros fatores podem estar presentes como o número de hematócrito e de granulócitos, a contaminação das CTH que serão infundidas, idade do receptor, comorbidades, método e tempo de infusão, assim como, a incompatibilidade ABO nos alogêni$\cos ^{(9-10)}$. A avaliação prévia das comorbidades do paciente é importante para que ele seja classificado quanto ao seu risco em realizar o TCTH, o que é feito por meio de um índice específico(12)

O enfermeiro tem atuação no TCTH e uma resolução do Conselho Federal de Enfermagem (COFEN) 0511/2016, regulamenta as atividades da equipe de enfermagem, neste contexto e descreve o enfermeiro como profissional imprescindivel na equipe multidisciplinar ${ }^{(13)}$.

Além disso, a portaria do Ministério da Saúde, no 931 de 02 de maio de 2006, aponta o enfermeiro como profissional obrigatório para o funcionamento da unidade de TCTH, tendo em vista seu conhecimento técnico e científico para o cuidado ao paciente grave, ao doador e à família(14). Deste modo, em diversos centros de TCTH, é de responsabilidade do enfermeiro a infusão das $\mathrm{CTH}$, assim como, grande parte de toda a assistência prestada no periodo pré e pós transplante ${ }^{(15)}$.

Considerando a suscetibilidade de pacientes de TCTH para o desenvolvimento de EA potencialmente graves, a possibilidade de intervenções precoces e a consequente redução de complicações para estes pacientes, os objetivos do presente estudo foram: Investigar os eventos adversos, classificá-los conforme a gravidade e identificar seus fatores relacionados no dia da infusão de células-tronco hematopoéticas.

\section{MÉTODO}

\section{Tipo de estudo}

Estudo transversal, com coleta prospectiva.

\section{Local do estudo}

O campo deste estudo foi uma unidade de TCTH do Estado de São Paulo, Brasil, que possui nove leitos. Estudo anterior apontou que, nesta unidade, os pacientes submetidos ao TCTH autólogo e alogênico ficaram hospitalizados, em média, por 34,7 dias (DP 19,5) e 34,3 dias (DP 14,1), respectivamente. Esta unidade de transplante apresenta média de 33 transplantes por ano (DP 7,0)(16).

\section{Participantes do estudo}

Considerando-se as particularidades anteriormente apresentadas sobre o local de estudo, optou-se pela avaliação de todos os transplantados no período da coleta de dados, ou seja, pela não realização do cálculo amostral.

Os pacientes elegíveis para o estudo foram aqueles com doenças onco-hematológicas submetidos ao TCTH autólogo ou alogênico. Como critério de exclusão considerou-se, aqueles pacientes cujos prontuários apresentavam dados incompletos, segundo as variáveis selecionadas no estudo.

A amostra foi consecutiva, por conveniência e inicialmente composta por 94 pacientes, o que correspondia ao total de pacientes transplantados na unidade, durante o período da coleta de dados. Entretanto, nove pacientes foram excluídos da pesquisa por dados incompletos, o que resultou em amostra final de 85 participantes.

\section{Coleta de dados}

Foi realizada por um período de 25 meses com término em janeiro de 2018, por meio de observação direta da pesquisadora, que é enfermeira assistencial da unidade de TCTH. Para isso, a pesquisadora utilizou um instrumento empregado 
mundialmente e nomeado 'Common Terminology Criteria for Adverse Events' (CTCAE)(11) . No periodo em que a pesquisadora não foi a responsável direta pela infusão de CTH, ela acompanhou o procedimento realizado por outros enfermeiros da unidade. Além da observação no momento da infusão de CTH, todos os registros da equipe multiprofissional foram utilizados, a fim de identificar e classificar os EA no momento da infusão e em até 24 horas após o procedimento.

Os dados foram validados por outra enfermeira da unidade previamente treinada para a utilização do instrumento, com larga experiência em TCTH, o que garantiu a fidedignidade da pesquisa. Quando houve discordância, um terceiro profissional, que era médico da unidade de TCTH realizou a avaliação e validação dos EA juntamente com a pesquisadora. A coleta de dados tinha início durante o TCTH propriamente dito e as informações, de até 24 horas após o transplante, eram coletadas assim que este intervalo de tempo findava.

Os EA (número e gravidade) foram considerados variáveis dependentes e as variáveis demográfico-clínicas foram analisadas como independentes (sexo, idade, índice do comorbidade para TCTH, diagnóstico, tipo de TCTH, fonte de CTH, tipo de condicionamento, tempo de infusão, volume da bolsa de CTH, número de células nucleadas, número de células CD34+, viabilidade celular, compatibilidade $A B O$, criopreservação e número de medicamentos utilizados em $D$ zero), as quais foram escolhidas a partir da literatura científica e da prática clínica da pesquisadora. Para avaliação do índice de comorbidade no TCTH foi utilizado instrumento validado ${ }^{(12)}$, que era preenchido previamente à internação do paciente, pela equipe médica e anexado ao seu prontuário.

\section{Procedimentos de análise e tratamento dos dados}

Para a avaliação dos EA, foi utilizado o CTCAE ${ }^{(11)}$, como mencionado anteriormente. Os EA são distribuidos por sistemas ou segmentos anatômicos e classificados conforme a gravidade, que varia de 1 até 5 , para a maioria dos EA. Para calcular a frequência e realizar as análises estatísticas referentes aos EA, foi necessário agrupá-los por sistemas orgânicos, conforme similaridade.

Os dados foram processados pelo programa Statistical Analysis System (SAS), versão 9.4. Para as associações utilizou-se o teste Qui-quadrado ou exato de Fisher, para as comparações o teste de Mann-Whitney e para as correlações entre as variáveis, o coeficiente de correlação de Spearman. Na avaliação da relação entre o conjunto de variáveis independentes e a variável dependente gravidade dos EA, foi construído um modelo de regressão logística multinomial. Quando a variável dependente foi o número dos EA, foi construido um modelo de regressão múltipla (modelos lineares generalizados); considerou-se o nivel de significância de $5 \%$ (17).

\section{Aspectos éticos}

Estudo aprovado pelo Comitê de Ética em Pesquisa (CAAE: 65311817.5.0000.5404). As normas regulamentadoras de pesquisas envolvendo seres humanos foram cumpridas e os participantes assinaram o termo de consentimento livre e esclarecido.

\section{RESULTADOS}

Cerca de $51 \%$ dos participantes era do sexo feminino, a média de idade foi de 50,9 anos (DP 12,5), 58,8\% apresentava índice de comorbidade classificado como de baixo risco, 52,9\% submetido ao TCTH alogênico aparentado e as doenças mais frequentes, que indicaram o TCTH, foram as leucemias (31,8\%) (Tabela 1$)$.

Tabela 1 - Características demográfico-clínicas dos pacientes submetidos ao transplante de células-tronco hematopoéticas. Campinas, SP, 2018.

\begin{tabular}{|c|c|c|}
\hline \multirow[t]{2}{*}{ Variáveis demográfico-clinicas } & \multirow[b]{2}{*}{$\mathrm{n}$} & \multirow[b]{2}{*}{ (\%) } \\
\hline & & \\
\hline \multicolumn{3}{|l|}{ Sexo } \\
\hline Feminino & 43 & 50,6 \\
\hline Masculino & 42 & 49,4 \\
\hline \multicolumn{3}{|l|}{ Idade em anos } \\
\hline Média (DP) & $50,9(12,5)$ & - \\
\hline Mediana (min-máx) & $53(21-73)$ & - \\
\hline \multicolumn{3}{|l|}{ Diagnóstico } \\
\hline Leucemias & 27 & 31,8 \\
\hline Linfomas & 25 & 29,4 \\
\hline Mieloma Múltiplo & 23 & 27,0 \\
\hline Outros* & 10 & 11,8 \\
\hline \multicolumn{3}{|l|}{ Tipo de TCTH } \\
\hline \multicolumn{3}{|l|}{ Alogênico aparentado } \\
\hline Idêntico & 45 & 52,9 \\
\hline Não Idêntico & 01 & 1,2 \\
\hline Alogênico não-aparentado & 01 & 1,2 \\
\hline Autólogo & 38 & 44,7 \\
\hline \multicolumn{3}{|l|}{ Índice de Comorbidade } \\
\hline Baixo Risco & 50 & 58,8 \\
\hline Risco Intermediário/Alto & 35 & 41,2 \\
\hline
\end{tabular}

Fonte: elaboração própria. *Outros= anemia aplástica; mielodisplasia; mielofibrose; amiloidose; síndrome de poems. 
Em relação às variáveis relacionadas ao TCTH, 90,6\% $(n=77)$ dos participantes receberam CTH provenientes de sangue periférico pelo método de aférese, $50,6 \%(n=43)$ foram de células criopreservadas e o crioprotetor mais utilizado foi o Dimethyl Sulfóxido (DMSO) a 10\% (34,1\%, n=29), seguido pelo DMSO a 10\% com Hidroxetilamido (HES) a $20 \%(16,5 \%, n=14)$. A média do número de células CD34 foi de $5,75 \times 10^{6}$ por quilo de peso do paciente (DP 5,24) e a de células nucleadas foi de $5,50 \times 10^{8}$ por quilo de peso do paciente (DP 2,34). Quanto às CTH infundidas, a viabilidade celular média encontrada foi de $96,64 \%$ (DP 5,80), o número de bolsas infundidas, variou de uma a seis unidades, com volume total médio de $374,44 \mathrm{ml}$ (DP 280,77 ) e a média de tempo utilizado para cada procedimento de infusão foi de 52 minutos (DP 23,92). Para os pacientes submetidos ao TCTH alogênico aparentado ou não, a incompatibilidade ABO esteve presente em $29,8 \%$ deles ( $n=14 / 47$ ).

Além disso, foram identificados 93 medicamentos diferentes nas prescrições médicas e o número médio de medicamentos utilizados pelos pacientes submetidos ao TCTH no dia da infusão de CTH foi de 13,11 (DP 3,12).

Quanto aos regimes de condicionamento prevaleceu, o mieloablativo $(68,2 \%, n=58)$, seguido do condicionamento de reduzida intensidade $(22,3 \%, n=19)$ e dos não mieloablativos $(9,5 \%, n=8)$. Os quimioterápicos mais utilizados foram - Bussulfano $(47 \%, n=40)$ nas apresentações oral $(n=19)$ e endovenoso $(n=21)$, Melfalano $(37,6 \%, n=32)$, Ciclofosfamida $(36,4 \%, n=31)$ e Fludarabina $(29,4 \%, n=25)$.

A Tabela 2 aponta a distribuição dos pacientes segundo as variáveis demográfico-clínicas e gravidade dos EA. De um modo geral, independentemente do tipo de TCTH, os pacientes com índice de comorbidade intermediário/ alto risco, apresentaram EA de maior gravidade (4 ou 5; $p=0,0019)$. Além disso, nos pacientes em que o DMSO foi utilizado como crioprotetor houve predomínio dos EA de média e alta complexidade $(p=0,0104)$.

Tabela 2 - Distribuição dos pacientes de TCTH segundo variáveis demográfico-clínicas e gravidade dos eventos adversos. Campinas, SP, 2018.

\begin{tabular}{|c|c|c|c|c|c|c|c|}
\hline \multirow{3}{*}{ Variáveis } & \multicolumn{6}{|c|}{ Gravidade eventos } & \multirow{3}{*}{ p-valor } \\
\hline & \multicolumn{2}{|c|}{$\begin{array}{l}1 \text { ou } 2 \\
\text { (Leve) }\end{array}$} & \multicolumn{2}{|c|}{$\begin{array}{l}3 \\
\text { (Moderado) }\end{array}$} & \multicolumn{2}{|c|}{$\begin{array}{l}4 \text { ou } 5 \\
\text { (Grave) }\end{array}$} & \\
\hline & n & $\%$ & $\mathbf{n}$ & $\%$ & $\mathbf{n}$ & $\%$ & \\
\hline Sexo & & & & & & & $0,5552^{*}$ \\
\hline Masculino & 13 & 30,95 & 17 & 40,48 & 12 & 28,57 & \\
\hline Feminino & 9 & 20,93 & 21 & 48,84 & 13 & 30,23 & \\
\hline
\end{tabular}

\begin{tabular}{|c|c|c|c|c|c|c|c|}
\hline \multicolumn{7}{|l|}{ Tipo de TCTH } & \multirow[t]{2}{*}{$0,2721^{*}$} \\
\hline Autólogo & 10 & 26,32 & 20 & 52,63 & 8 & 21,05 & \\
\hline Alogênico & 12 & 25,53 & 18 & 38,30 & 17 & 36,17 & \\
\hline $\begin{array}{l}\text { Diagnóstico } \\
\text { que indica o } \\
\text { TCTH }\end{array}$ & & & & & & & $0,0733^{\star \star}$ \\
\hline Leucemia & 7 & 25,93 & 10 & 37,04 & 10 & 37,04 & \\
\hline Linfoma & 8 & 32,00 & 10 & 40,00 & 7 & 28,00 & \\
\hline $\begin{array}{l}\text { Mieloma } \\
\text { múltiplo }\end{array}$ & 6 & 26,09 & 15 & 65,22 & 2 & 8,70 & \\
\hline Outros & 1 & 10,00 & 3 & 30,00 & 6 & 60,00 & \\
\hline $\begin{array}{l}\text { Tipo de } \\
\text { condiciona- } \\
\text { mento }\end{array}$ & & & & & & & $0,2577^{\star}$ \\
\hline $\begin{array}{l}\text { Não Mielo- } \\
\text { ablativo/RIC }\end{array}$ & 9 & 37,50 & 8 & 33,33 & 7 & 29,17 & \\
\hline Mieloablativo & 13 & 21,31 & 30 & 49,18 & 18 & 29,51 & \\
\hline $\begin{array}{l}\text { Índice de } \\
\text { Comorbidade }\end{array}$ & & & & & & & $0,0019^{*}$ \\
\hline Baixo & 18 & 36,00 & 24 & 48,00 & 8 & 16,00 & \\
\hline $\begin{array}{l}\text { Intermediá- } \\
\text { rio/Alto }\end{array}$ & 4 & 11,43 & 14 & 40,00 & 17 & 48,57 & \\
\hline $\begin{array}{l}\text { Incompa- } \\
\text { tibilidade } \\
\text { ABO }\end{array}$ & & & & & & & $0,1306^{* *}$ \\
\hline Compativel & 11 & 33,33 & 10 & 30,30 & 12 & 36,36 & \\
\hline $\begin{array}{l}\text { Não compa- } \\
\text { tível }\end{array}$ & 1 & 7,14 & 8 & 57,14 & 5 & 35,71 & \\
\hline Autólogo & 10 & 26,32 & 20 & 52,63 & 8 & 21,05 & \\
\hline $\begin{array}{l}\text { Criopreser- } \\
\text { vação }\end{array}$ & & & & & & & $0,2399^{*}$ \\
\hline Não & 12 & 28,57 & 15 & 35,71 & 15 & 35,71 & \\
\hline Sim & 10 & 23,26 & 23 & 53,49 & 10 & 23,26 & \\
\hline Crioprotetor & & & & & & & $0,0104^{* *}$ \\
\hline DMSO & 4 & 13,79 & 15 & 51,72 & 10 & 34,48 & \\
\hline DMSO+HES & 6 & 42,86 & 8 & 57,14 & 0 & 0,00 & \\
\hline $\begin{array}{l}\text { Fonte de } \\
\text { células }\end{array}$ & & & & & & & $0,2465^{\star \star}$ \\
\hline Óssea & 1 & 12,50 & 6 & 75,00 & 1 & 12,50 & \\
\hline CPP & 21 & 27,27 & 32 & 41,56 & 24 & 31,17 & \\
\hline
\end{tabular}

Fonte: elaboração própria. * $p$-valor obtido pelo teste Qui-quadrado; **teste exato de Fisher.

A Tabela 3 apresenta a distribuição das médias de ocorrência dos EA segundo tipo de TCTH e sistemas orgânicos, conforme divisão do CTCAE; não houve diferença estatística significante entre os grupos comparados em relação à média de ocorrência dos EA. 
Tabela 3 - Distribuição das médias de ocorrência dos eventos adversos segundo tipo de transplante de células-tronco hematopoéticas e sistemas orgânicos. Campinas, SP, 2018.

\begin{tabular}{|l|l|l|l|l|l|}
\hline \multicolumn{7}{|l|}{ Dia da Infusão (D Zero) } & \multicolumn{2}{l}{ Alogênico } & \\
\hline & Autólogo & & \\
\hline \multirow{2}{*}{$\begin{array}{l}\text { Sistemas } \\
\text { Orgânicos }\end{array}$} & Média EA & DP & Média EA & DP & \\
\cline { 2 - 5 } & 1,21 & 0,47 & 1,15 & 0,75 & $0,3186^{*}$ \\
\hline Grupo 1 & 5,24 & 2,49 & 6,02 & 2,46 & $0,2217^{*}$ \\
\hline Grupo 2 & 0,29 & 0,57 & 0,30 & 0,66 & $0,8361^{*}$ \\
\hline Grupo 3 & 1,29 & 1,14 & 1,13 & 0,95 & $0,6247^{*}$ \\
\hline Grupo 4 & 0,66 & 0,75 & 0,74 & 0,87 & $0,7797^{*}$ \\
\hline Grupo 5 & 0,50 & 0,76 & 0,45 & 0,95 & $0,2873^{*}$ \\
\hline Grupo 6 & & & & & \\
\hline
\end{tabular}

Fonte: elaboração própria. *p-valor obtido pelo teste de Mann-Whitney. $\mathbf{1 = a l t e r a c ̧ o ̃ e s ~ c a r d i a c a s ~ e ~ v a s c u l a - ~}$ res; $\mathbf{2}=$ alterações do sistema sanguíneo e linfático, do metabolismo e nutrição, investigações laboratoriais, alterações do sistema imunológico; $\mathbf{3}=$ alterações do sistema nervoso e psiquiátricas; $\mathbf{4 = a l t e r a c ̧ o ̃ e s ~ g a s t r o i n - ~}$ testinais; $\mathbf{5}=$ alterações gerais e condições do sítio de administração; $\mathbf{6}=$ alterações respiratória, torácica e mediastinal.

A frequência das alterações renais e urinárias (hemoglobinúria), nos grupos autólogo e alogênico, classificadas como grau 1 , foi de $52,6 \%(n=20)$ nos autólogos e de $10,6 \%(n=5)$ nos alogênicos com CTH criopreservadas $(p<0,0001)$. As lesões, intoxicações e complicações de procedimentos, bem como, as infecções e infestações estiveram presentes em $7,89 \%(n=3)$ dos autólogos e em $21,28 \%(n=10)$ dos alogênicos ( $p=0,0883)$; nas alterações de pele, olhos e metrorragia, estes EA estiveram presentes em 10,53\% ( $n=4)$ dos autólogos e em 21,28\% $(n=10)$ dos alogênicos $(p=0,1840)$.

A Tabela 4 apresenta a relação entre a maior viabilidade celular $(p=0,035)$ e o índice de comorbidade específico para o TCTH $(p=0,004)$ com a gravidade dos EA apresentados pelos pacientes no dia da infusão de CTH.
Tabela 4 - Variáveis independentes que constituíram a análise de regressão logística multinomial em que se considerou a gravidade dos eventos adversos. Campinas, SP, 2018.

\begin{tabular}{|c|c|c|c|c|c|}
\hline \multirow[t]{4}{*}{$\begin{array}{l}\text { Variável } \\
\text { dependente }\end{array}$} & $\begin{array}{l}\text { Variáveis inde- } \\
\text { pendentes }\end{array}$ & $\mathrm{OR}^{* *}$ & \multicolumn{2}{|c|}{ IC $(95 \%)^{* * *}$} & \multirow{2}{*}{$\begin{array}{c}\text { p-valor } \\
0,1117\end{array}$} \\
\hline & Idade & 1,032 & 0,993 & 1,074 & \\
\hline & $\begin{array}{l}\text { № células } \\
\text { CD } 34^{+} / \mathrm{Kg} / \text { peso } \\
\text { receptor }\end{array}$ & 1,004 & 0,914 & 1,102 & 0,9408 \\
\hline & $\begin{array}{l}\text { № células } \\
\text { nucleadas/Kg/ } \\
\text { peso receptor }\end{array}$ & 1,083 & 0,893 & 1,312 & 0,4185 \\
\hline \multirow[t]{8}{*}{$\begin{array}{l}\text { Gravidade } \\
\text { eventos }{ }^{*}\end{array}$} & $\begin{array}{l}\text { Viabilidade } \\
\text { celular }\end{array}$ & 1,092 & 1,006 & 1,185 & 0,0352 \\
\hline & $\begin{array}{l}\text { Volume total } \\
\text { bolsas infundi- } \\
\text { das }(\mathrm{ml})\end{array}$ & 1,000 & 0,998 & 1,002 & 0,8550 \\
\hline & $\begin{array}{l}\text { № medicamen- } \\
\text { tos }\end{array}$ & 1,119 & 0,955 & 1,310 & 0,1634 \\
\hline & Sexo (Feminino) & 1,294 & 0,503 & 3,329 & 0,5923 \\
\hline & $\begin{array}{l}\text { Tipo de TCTH } \\
\text { (Alogênico) }\end{array}$ & 3,244 & 0,398 & 26,443 & 0,2717 \\
\hline & $\begin{array}{l}\text { Tipo de con- } \\
\text { dicionamento } \\
\text { (Mieloablativo) }\end{array}$ & 2,296 & 0,669 & 7,875 & 0,1864 \\
\hline & $\begin{array}{l}\text { Índice de } \\
\text { Comorbidade } \\
\text { (Intermediário/ } \\
\text { Alto) }\end{array}$ & 4,205 & 1,581 & 11,182 & 0,0040 \\
\hline & $\begin{array}{l}\text { Criopreserva- } \\
\text { ção (Sim) }\end{array}$ & 1,899 & 0,254 & 14,178 & 0,5320 \\
\hline
\end{tabular}

Fonte: elaboração própria. * Estimada a chance de apresentar níveis mais elevados de gravidade (variável dependente) ${ }^{* *} \mathrm{OR}=$ (Odds Ratio). *** IC 95\% $\mathrm{OR}=$ intervalo de $95 \%$ de confiança para a razão de chance.

A Tabela 5 mostra que houve relação estatística significante entre o número de EA e o maior volume total de bolsas infundidas $(p=0,0011)$, tipo de TCTH - alogênico $(p=0,0093)$, o diagnóstico que indica o TCTH (linfoma $p=0,0001$ e mieloma múltiplo $-p=0,0136)$, maiores índices de comorbidade específico para o TCTH $(p=0,0010)$, a criopreservação $(p=0,0023)$ e a maior viabilidade celular $(p=<0,0001)$. 
Tabela 5 - Variáveis independentes que constituíram a análise de regressão múltipla em que se considerou o número de eventos adversos. Campinas, SP, 2018.

\begin{tabular}{|c|c|c|c|c|c|}
\hline \multirow[t]{4}{*}{$\begin{array}{l}\text { Variável } \\
\text { depen- } \\
\text { dente }\end{array}$} & $\begin{array}{l}\text { Variáveis indepen- } \\
\text { dentes }\end{array}$ & * & \multicolumn{2}{|c|}{ IC $(95 \%)^{\star * *}$} & \multirow{2}{*}{$\begin{array}{l}\text { p-valor } \\
0,7415\end{array}$} \\
\hline & Idade & $-0,012$ & $-0,080$ & 0,057 & \\
\hline & $\begin{array}{l}\text { № células CD } 34^{+} / \mathrm{Kg} / \\
\text { peso }\end{array}$ & $-0,043$ & $-0,195$ & 0,109 & 0,5812 \\
\hline & $\begin{array}{l}\text { № células nucleadas/ } \\
\mathrm{Kg} / \text { peso }\end{array}$ & 0,203 & $-0,136$ & 0,541 & 0,2407 \\
\hline \multirow{11}{*}{$\begin{array}{l}\text { Núme- } \\
\text { ro de } \\
\text { eventos }\end{array}$} & Viabilidade celular & 0,294 & 0,150 & 0,438 & $<0,0001$ \\
\hline & $\begin{array}{l}\text { Volume total de bolsas } \\
\text { infundidas }\end{array}$ & 0,006 & 0,003 & 0,010 & 0,0011 \\
\hline & № medicamentos & 0,176 & $-0,096$ & 0,447 & 0,2047 \\
\hline & Sexo (Feminino) & 0,279 & $-1,300$ & 1,858 & 0,7295 \\
\hline & $\begin{array}{l}\text { Tipo de TCTH (Alogê- } \\
\text { nico) }\end{array}$ & 4,990 & 1,228 & 8,752 & 0,0093 \\
\hline & $\begin{array}{l}\text { Diagnóstico que indica } \\
\text { o TCTH (Linfoma) }\end{array}$ & 5,151 & 2,524 & 7,779 & 0,0001 \\
\hline & $\begin{array}{l}\text { Diagnóstico que } \\
\text { indica o TCTH (Mieloma } \\
\text { Múltiplo) }\end{array}$ & 3,481 & 0,718 & 6,245 & 0,0136 \\
\hline & $\begin{array}{l}\text { Diagnóstico que indica } \\
\text { o TCTH (Outros) }\end{array}$ & $-0,287$ & $-2,953$ & 2,378 & 0,8327 \\
\hline & $\begin{array}{l}\text { Tipo de } \\
\text { condicionamento } \\
\text { (Mieloablativo) }\end{array}$ & 1,776 & $-0,550$ & 4,101 & 0,1344 \\
\hline & $\begin{array}{l}\text { Índice de } \\
\text { Comorbidade } \\
\text { (Intermediário/Alto) }\end{array}$ & 2,786 & 1,127 & 4,445 & 0,0010 \\
\hline & Criopreservação (Sim) & 5,398 & 1,934 & 8,862 & 0,0023 \\
\hline
\end{tabular}

Fonte: elaboração própria. * =coeficiente de regressão. ${ }^{* *} \mathrm{IC}=$ intervalo de $95 \%$ de confiança.

\section{DISCUSSÃO}

Referente aos dados demográfico-clínicos dos participantes, foi observado que o TCTH prevalente no centro pesquisado foi o alogênico $(55,3 \% ; n=47)$. De um modo geral, nota-se um predomínio do TCTH autólogo, o que pode ser justificado devido às suas indicações para diversas doenças, como tumores sólidos, diabetes e doenças autoimunes $^{(18)}$

Quanto ao diagnóstico que indica o TCTH, foi observado a prevalência do diagnóstico de leucemia (31,8\%; $n=27)$, realidade presente em estudos semelhantes, nos quais as leucemias são a principal indicação para o TCTH alogêni$\mathrm{co}^{(9)}$. No mundo, este tipo de câncer ocupa o llo lugar e no Brasil ocupa a 9ㅇ posição(19)
Estudos apontam que os EA apresentados pelos pacientes submetidos ao TCTH, como alterações laboratoriais, bem como relativas ao sistema sanguíneo e linfático são inerentes aos regimes de condicionamento, principalmente quando altas doses de quimioterápicos são utilizadas. Alterações metabólicas e gastrointestinais, são decorrentes de diversos medicamentos administrados neste período(20). Alguns antineoplásicos como Ciclofosfamida, Melfalano, Bussulfano, causam toxicidade gastrointestinal, como náuseas e vômitos. A irradiação corporal total (ICT) e outros medicamentos como antibióticos, antifúngicos e imunossupressores também podem contribuir para o aparecimento ou intensificação destes EA ${ }^{(20-21)}$.

Quanto às alterações renais e urinárias (hemoglobinúria), os pacientes de TCTH autólogo apresentaram maior frequência destes $E A(p<0,0001)$, fato que pode ser atribuido à criopreservação das CTH, especialmente, quando realizada com o DMSO. No período de descongelamento das CTH, pode ocorrer lise celular das células vermelhas do sangue e presença de hemoglobina livre, o que resulta em hemoglobinúria( ${ }^{(7)}$.

No que diz respeito ao tipo de TCTH, o alogênico contribuiu para um aumento de 4,99 no número de EA, em média, em comparação com o autólogo ( $p=0,0093)$. No TCTH alogênico, usa-se imunossupressores devido às reações aloimunes e para prevenção da doença do enxerto contra o hospedeiro (DECH), que podem contribuir para o maior número de EA, ou para potencializá-los, no dia da infusão de $\mathrm{CTH}^{(22)}$.

Neste estudo, foi observado que pacientes, no momento do TCTH, com índice de comorbidade considerado intermediário ou de alto risco, apresentaram maior ocorrência de EA ( $p=0,0010$ ) e EA de maior gravidade (4 ou 5; $p=0,0040$ ). A chance do paciente, que apresenta o índice de comorbidade de intermediário a alto risco, no momento do TCTH, é igual a 4,21 vezes a chance do paciente de baixo risco de apresentar EA de maior gravidade. Do mesmo modo, foi observado que o paciente submetido ao TCTH que apresenta o índice de comorbidade entre intermediário a alto risco tem um aumento médio de 2,78 no número de EA, comparado ao paciente que apresenta baixo risco.

Outros estudos associaram a presença de comorbidades com pior prognóstico de pacientes oncológicos ${ }^{(12,23)}$. Desta forma, a avaliação clínica rigorosa do paciente, que inclua a realização de um índice de comorbidade, pode estimar os riscos de morbimortalidade.

Os pacientes que tiveram as $\mathrm{CTH}$ criopreservadas, apresentaram maior número de EA ( $p=0,0023)$. Observou-se maior número e gravidade dos EA, com o uso de DMSO, 
comparados àqueles que utilizaram DMSO associado ao HES ( $p=0,0205)$. Deste modo, os pacientes que receberam enxerto criopreservado apresentaram aumento médio de 5,39 no número de EA, comparado aos pacientes que receberam CTH a fresco. Este achado é corroborado por estudos semelhantes, que citam a possivel toxicidade do crioprotetor DMSO, que provoca a liberação de histaminas no paciente. A associação do uso do HES ao DMSO tem o objetivo de reduzir EA nos pacientes submetidos ao TCTH, pois propicia a formação de uma camada protetora nas células progenitoras, o que reduz o dano celular e, consequentemente, $\mathrm{EA}^{(24)}$

O volume total de bolsas infundidas no dia da infusão de CTH apresentou relação com o número de EA ( $p=0,0011)$. $\mathrm{Pa}$ cientes que receberam maior volume de bolsas no momento do TCTH tem um aumento médio de 0,006 no número de EA. Tal fato pode ser atribuido à maior quantidade de detritos de granulócitos, hemoglobina livre nos autólogos, assim como, à incompatibilidade celular no grupo alogênico(25-26).

A maior média de viabilidade celular apresentou relação com o número e a gravidade dos $E A$ ( $p<0,0001 ; p=0,0352$ ), respectivamente. $O$ paciente que apresentou a maior viabilidade celular das CTH coletadas, apresentou uma maior chance de apresentar EA de maior gravidade, no momento da infusão de CTH - 1,09 vezes a chance do grupo com menor viabilidade celular, bem como, apresentou um aumento de 0,29 no número de EA. Na literatura é demonstrado que no processo de criopreservação, a viabilidade das células CD34 $4^{+}$pode estar comprometida, bem como a redução de células viáveis para a infusão. A viabilidade celular difere entre os períodos pré e pós congelamento, estando relacionado com a baixa temperatura, a formação de cristais de gelo ou o uso do DMSO(6)

A utilização de estratégias, que proporcionem ao enfermeiro e aos demais membros da equipe multiprofissional, o reconhecimento precoce das condições que levam o paciente de TCTH a apresentar EA, facilita o planejamento da assistência e controle desses EA no dia da infusão das $\mathrm{CTH}^{(27-29)}$.

\section{Limitações do estudo}

Variáveis que não puderam ser analisadas estatisticamente devido à baixa frequência, como o controle microbiológico, método de infusão e valor de hematócrito, que podem ser possiveis causas ou potencializadores dos EA na infusão das CTH.

\section{Contribuições para a prática}

Os resultados incentivam a busca de novos conhecimentos sobre o cuidado de Enfermagem no TCTH. A utilização de instrumentos, como o CTCAE e o do índice de comorbidade pré-transplante, é importante, pois, contribui para a identificação e resolução precoce de EA, o que pode contribuir para uma assistência de saúde mais segura.

\section{CONCLUSÃO}

Neste estudo, os fatores relacionados à ocorrência de EA no dia da infusão de CTH foram viabilidade celular, indice de comorbidade pré-TCTH (intermediário a alto), maior volume de bolsas de CTH infundidas, transplante alogênico, diagnósticos de linfoma e mieloma múltiplo e criopreservação.

\section{Contribuições dos autores:}

Concepção e/ou desenho do estudo - Andressa Gomes Melo e Juliana Bastoni da Silva. Coleta, análise e interpretação dos dados - Andressa Gomes Melo. Redação e/ ou revisão crítica do manuscrito - Andressa Gomes Melo e Juliana Bastoni da Silva. Aprovação da versão final a ser publicada - Juliana Bastoni da Silva.

\section{REFERÊNCIAS}

1. Voltarelli JC. História do Transplante de Células-Tronco Hematopoéticas no Brasil e no Mundo. In: Thomas ED, Voltarelli JC, Ferreira E, Pasquini R. Transplante de Células-Tronco Hematopoéticas. São Paulo: Atheneu: 2009. p. 03-42.

2. Antin JH, Raley DY. Types of transplantation. In: Antin JH, Raley DY. Manual of stem cell and bone marrow transplantation. Cambridge: Cambridge University Press; 2013. p. 3-5.

3. Worldwide Network for Blood and Marrow Transplantation [internet]. Switzerland; 2006-2013. Disponivel em: www.wbmt.org
4. Associação Brasileira de Transplante de Órgãos. Registro Brasileiro de Transplantes. Dimensionamento dos Transplantes no Brasil e em cada estado. Ano XXV no 4. (2012-2019). Disponivel em: www.abto. org.br

5. Mulay SB, Greiner CW, Mohr A, Bryant SC, Lingineni RK, Padley D, et al. Infusion technique of hematopoietic progenitor cells and related adverse events. Transfusion. 2014; 54(8):1997-2003.

6. Shu Z, Heimfeld S, Gao D. Hematopoietic SCT with cryopreserved grafts: adverse reactions after transplantation and cryo- 
protectant removal before infusion. Bone Marrow Transplant. 2014: 49(4):469-76.

7. Bear AS, Hanley PJ, Bosque DM, Cruz CR, Kaur I, Liu H, et al. Low rate of infusional toxicity after expanded cord blood transplantation. Cytotherapy. 2014; 16(8):1153-7.

8. Hamerschlak N. Haploidentical transplantation of hematopoietic stem cells. Rev Assoc Med Bras. 2016; 62 (Suppl 1): 29-33.

9. Canaani J, Savani BN, Labopin M, Huang XJ, Ciceri F, Arcese W, et al. Donor age determines outcome in acute leukemia patients over 40 undergoing haploidentical hematopoietic cell transplantation. Am J Hematol. 2018; 93(2):246-53.

10. Vidula N, Villa M, Helenowski IB, Merchant M, Jovanovic BD, Meagher R, et al. Adverse Events During Hematopoietic Stem Cell Infusion: Analysis of the Infusion Product. Clin Lymphoma Myeloma Leuk. 2015; 15(11):157-62.

11. National Cancer Institute. Common Terminology Criteria for Adverse Events . 2010; 4(3):1-80. Disponivel em: https://www.eortc. be/services/doc/ctc

12. Sorror ML, Logan BR, Zhu X, Rizzo JD, Cooke KR, McCarthy PL, et al. Prospective Validation of the Predictive Power of the Hematopoietic Cell Transplantation Comorbidity Index: A Center for International Blood and Marrow Transplant Research Study. Biol Blood Marrow Transplant. 2015; 21(8):1479-87.

13. Conselho Federal de Enfermagem(Cofen). Resolução $n$ 으 0511/2016. Aprova a norma técnica que dispõe sobre a atuação de enfermeiros e técnicos de enfermagem em hemoterapia. Diário Oficial da União. 4 abr 2016. Disponivel em: http://www.cofen.gov.br/ resolucao-cofen-no-05112016_39095.html

14. Ministério da Saúde (BR). Portaria no 931 de 02 de maio de 2006. Dispõe sobre o regulamento técnico para transplante de células-tronco hematopoéticas. Diário Oficial da União. 2006. Disponivel em: http://www.redsang.ial.sp.gov.br/site/docs_leis/ps/ps4.pdf

15. Lima K, Bernardino E. Nursing care in a hematopoietic stem cells transplantation unit. Text Context Nursing. 2014; 23(4):845-853.

16. Silva JB, Póvoa VC, Lima MH, Oliveira HC, Padilha KG, Secoli SR. Nursing workload in hematopoietic stem cell transplantation: a cohort study. Rev Esc Enferm USP. 2015; 49 (Esp):92-98

17. Pagano M, Gauvreau K. Principios de Bioestatística. $2^{a}$ ed. São Paulo: Thomson; 2004.

18. Kanate AS, Majhail NS, Savani BN, Bredeson C, Champlin RE, Crawford S, et al. Indications for Hematopoietic Cell Transplanta- tion and Immune Effector Cell Therapy: Guidelines from the American Society for Transplantation and Cellular Therapy: Guidelines for Hematopoietic Transplantation and Cellular Therapy. Biol Blood Marrow Transplant. 2020; 26(7):1247-56.

19. Instituto Nacional de Câncer. Incidência de câncer no Brasil. Estimativa 2018 [Internet]. 2018. Disponivel em: http://wwwl.inca.gov. br/estimativa/2018/estimativa-2018.pdf

20. Fischer-Cartlidge EA. Assessment and management of gastrointestinal toxicities and lab abnormalities related to targeted therapy. Semin Oncol Nurs. 2014; 30(3):183-9.

21. Antin JH, Raley DY. Transplant-related complications. In: In: Antin JH, Raley DY. Manual of stem cell and bone marrow transplantation. Cambridge: Cambridge University Press; 2013. p. 47.

22. Truong TH, Moorjani R, Dewey D, Guilcher GM, Prokopishyn NL, Lewis VA. Adverse reactions during stem cell infusion in children treated with autologous and allogeneic stem cell transplantation. Bone Marrow Transplant. 2016; 51(5):680-6.

23. Keller JW, Andreadis C, Damon LE, Kaplan LD, Martin TG, Wolf $J$, et al. Hematopoietic cell transplantation comorbidity index (HCT-CI) is predictive of adverse events and overall survival in older allogeneic transplant recipients. J Geriatr Oncol. 2014: 5(3):238-44

24. Zhu F, Heditke S, Kurtzberg J, Waters-Pick B, Hari P. Margolis DA et al. Hydroxyethyl starch as a substitute for dextran 40 for thawing peripheral blood progenitor cell products. Cytotherapy. 2015 17(12):1813-9.

25. Tekgündüz SA, Özbek N. ABO blood group mismatched hematopoietic stem cell transplantation. Transfus Apher Sci. 2016; 54(1):249.

26. Forster F, Câmara AL, Moraes CLK, Honório MT, Mattia D, Lazzari DD. Percepção dos enfermeiros quanto à assistência de Enfermagem no processo transfusional. Enferm. Foco. 2018; 9(3):71-5.

27. Marques ACB, Proença SFFS, Machado CAM, Guimarães PRB Maftum MA, Kalinke LP. Quality of life in the first six months post-hematopoietic stem cell transplantation. Text Context Nursing. 2017: 26(3):1-11.

28. Timurağaoğlu A. The role of the nurses and technicians for stem cell mobilisation and collection. Transfus Apher Sci. 2015:53(1):30-3.

29. Ikeda K, Ohto H, Okuyama Y, Yamada-Fujiwara M, Kanamori H Fujiwara SI, et al. Adverse Events Associated With Infusion of Hematopoietic Stem Cell Products: A Prospective and Multicenter Surveillance Study. Transfus Med Rev. 2018; 32:186-94. 